\title{
Diásporas e comunidades quilombolas: perspectivas metodológicas para o ensino de história da África e da cultura afro-brasileira
}

Diaspora and maroon communities: methodological perspectives for the teaching of African history and African-Brazilian culture

Maria Walburga dos Santos*

Ana Cristina Juvenal da Cruz ${ }^{*}$

\section{RESUMO}

A institucionalização do ensino de história da África e de cultura afro-brasileira nas escolas abriu caminho para o debate acerca da inserção desses conteúdos nos currículos de história. O precedente levou os historiadores a se perguntarem sobre o conteúdo e o ensino dessa história e da cultura produzida pelos povos africanos e por seus descendentes. Este texto é estruturado com base em duas possibilidades metodológicas para esse ensino: a diáspora e as comunidades quilombolas. Apresentamos elementos para uma metodologia e uma didática do ensino de história que considerem as experiências diaspóricas das populações negras e o espaço do quilombo como local de recriação cultural de elementos africanos. Analisamos o percurso histórico que culminou na institucionalização desse ensino e alguns elementos relacionados a esses conteúdos. Palavras-chave: ensino de história da África; diáspora; comunidades quilombolas.

\section{Abstract}

The institutionalization of the teaching of African history and African-Brazilian culture in the schools gave way to the debate about the inclusion of such content in the curriculums of history. This precedent has led historians to wonder about the content and teaching of that history and of the culture produced by African peoples and their descendants. This text is structured upon two methodological possibilities for the teaching of those themes: the Diaspora and maroon communities. We present some elements for a methodology and a didactic of teaching history that consider the experiences of black diasporic space and maroon communities as a place of recreation of cultural elements of Africa. We analyze the historical background that led to the institutionalization of the teaching of African history and African-Brazilian culture and show some aspects of these subjects. Keywords: teaching of African history; diaspora; maroon communities.

\footnotetext{
* Departamento de Teorias e Práticas Pedagógicas, Universidade Federal de São Carlos (DTPP/ UFSCar). Via Washington Luís, km 235, Caixa Postal 676. 13545-905 São Carlos - SP - Brasil. walburga@ufscar.br

** Doutoranda em Educação, Bolsista Capes. Universidade Federal de São Carlos. Via Washington Luis, km 235. 13545-905 São Carlos - SP - Brasil. a_amhara@yahoo.com.br
} 
Uma das problemáticas mais acentuadas acerca do ensino de história se deve à construção metodológica desse ensino e do conteúdo a ser ofertado. Esse debate há muito tempo é objeto de estudos no campo do currículo e da didática, e sofreu uma inflexão com a obrigatoriedade do ensino de história da África e das culturas afro-brasileira e africana nas instituições de ensino brasileiras por meio da Lei 10.639/2003 e do Parecer CNE/CP 003/2004, referente às Diretrizes Curriculares Nacionais para Educação das Relações Étnico-raciais e para o Ensino de História Afro-Brasileira e Africana.

As questões acerca dos elementos constitutivos de como e o que ensinar emergiram das políticas curriculares voltadas para a inserção desses conteúdos. As pesquisas sobre ensino e 'prática escolar' ${ }^{1}$ impulsionadas pela ascensão da pós-graduação brasileira nos anos 1970 redimensionaram os debates sobre o ensino de conteúdos específicos. A incorporação de outras metodologias, como a etnografia, também possibilitou novas leituras do espaço escolar. No que diz respeito ao ensino de história, a questão central se refere à utilização das fontes no ensino.

Esses desafios têm questionado a maneira pela qual o campo historiográfico descreveu as experiências dos povos africanos e de seus descendentes. As pesquisas acerca da institucionalização do ensino de história da África e das culturas africana e afro-brasileira têm apontado que as maiores dificuldades se referem ao uso de materiais didáticos e à formação de historiadores para seu ensino. Muitos cursos têm sido oferecidos para as diversas modalidades de ensino, e, embora os resultados tenham sido satisfatórios, os dados mostram que essas dificuldades impedem a construção de metodologias que atendam as necessidades curriculares da história africana e afro-brasileira. Tais medidas somente alcançarão os objetivos propostos se houver a incorporação de um novo paradigma de educação das relações étnico-raciais brasileiras. Isso abre a necessidade de debates sobre questões epistemológicas e métodos de ensino.

Muitas atribuições já foram relacionadas à finalidade do estudo e do ensino de história: 'fortalecer a nação', 'fortalecer uma identidade nacional', 'construir uma comunidade' mesmo que 'imaginada'. ${ }^{2}$ Hoje, a compreensão do caráter imaginado das nações é algo menos conflituoso, atrelado a termos como nacionalidade, pertencimento e identidade, entre outros, e à maneira como esse caráter imaginário é um 'produto cultural' (Anderson, 2008, p.30). Uma das questões a serem resolvidas se refere às fontes utilizadas na produção 
da história e, consequentemente, à análise feita sobre elas. 'Povos sem história', 'sem escrita' e 'sem cultura', entre outras representações, foram expressões atribuídas aos povos que se encontravam fora do círculo restrito da história. ${ }^{3}$ Isso tem sido reavaliado de forma crítica em relação ao modo pelo qual se construiu a história que valeria a pena ser contada, no qual a produção europeia - e mais recentemente a dos Estados Unidos - se localiza em um centro difusor e orientador dos saberes.

Esse conjunto de representações e de estereótipos sobre tais grupos orientou a produção historiográfica e um modo de olhar e de construir de forma binária um 'nós' e um 'eles', ou seja, um discurso sobre um 'Outro'. Os estudos pós-coloniais que ascenderam ao discurso teórico a partir dos anos 1980 se configuraram como um espaço de crítica das maneiras pelas quais os conhecimentos são construídos. Como escapar a esse conjunto de discursos presentes na construção historiográfica sobre os africanos e seus descendentes?

Um desdobramento está diretamente ligado à linguagem. Fanon ${ }^{4}$ aponta a maneira pela qual a construção da linguagem sobre a colonização e o lugar dos negros nesse processo se constituíram historicamente. Essa linguagem é marcada pelas dimensões de gênero e de experiência e por uma esfera racial, o que permitiu a construção de um conjunto de discursos construídos racialmente sobre aqueles que foram colocados no lugar do 'Outro'. Esse 'Outro' é localizado em um território, passa a ter determinadas características físicas que o definem moral e psicologicamente.

Ao constituírem determinada linguagem, essas representações apropriam-se de nossos cotidianos, informando-nos e oferecendo um determinado conjunto de saberes sobre esses 'Outros'. Práticas e representações em torno do que se refere à África ou aos descendentes de africanos podem ser compreendidas pela noção de racialização à qual esses povos foram relegados. A racialização é relacionada a um processo de categorização pelo qual um grupo (seja étnico, racial ou de gênero) é identificado como pertencente a um dos agrupamentos que são definidos por critérios arbitrários como o fenótipo, uma tradição cultural ou ainda religiosa. ${ }^{5}$

Isso significa afirmar que a linguagem é racialmente determinada e o sujeito, ao entrar na linguagem, está inserido em um universo racializado. $\mathrm{O}$ termo 'Continente negro' em referência ao Continente africano é um exemplo dessa natureza racial na qual a linguagem está inserida, visto que outros con- 
tinentes não têm um epíteto racial como esse. 'Negro' tornou-se sinônimo de uma essência racializante na qual toda uma linguagem adjetivada de inferioridade fixava os africanos e seus descendentes em tais estereótipos. ${ }^{6}$

Essa narrativa em torno do vocábulo negro é, no entanto, ressignificada. $\mathrm{Hall}^{7}$ argumenta como esse termo tem articulado a noção de negritude, ${ }^{8}$ como um movimento identitário. Munanga aponta duas dimensões para que se compreenda a ressignificação do termo 'negro' e da negritude: o sentido e a experiência. ${ }^{9}$ Essas duas dimensões operam de forma simultânea, o sentido se refere ao contexto no qual 'ser Negro' pode ser experienciado, a linguagem, portanto é construída em um campo histórico e dinâmico, produzindo sentidos e subjetividades.

Durante muito tempo os povos e as nações africanos entraram na história provindo de uma demarcação no interior da linguagem racializada. O lugar conferido à história de mulheres e homens africanos e seus descendentes esteve relegado à semântica da escravidão e, posteriormente, do colonialismo. Alguns historiadores inspirados por uma determinada lógica desconsideraram as resistências e as maneiras pelas quais esses povos ressignificaram suas existências sob a experiência violenta da escravidão, do colonialismo e de suas consequências. Tais noções combinadas estabeleceram as hierarquizações de inferioridade e superioridade entre os grupos étnicos, as quais, sob os auspícios da ciência da época, justificaram a escravização dos povos africanos e de seus descendentes e a 'missão civilizatória' que marcou a modernidade. No Brasil, o que tem sido denominado de 'nova historiografia da escravidão' ou 'história social da escravidão’ passou a atribuir um caráter protagonista aos negros e à sua experiência e ação em relação ao escravismo.

A possibilidade aberta pela legislação para o ensino de história da África e da cultura afro-brasileira colocou na pauta do debate historiográfico as disponibilidades e os usos das fontes para a pesquisa. As fontes orais se colocam como um dado apropriado na pesquisa histórica, sem se opor às fontes documentais que secularizaram exclusivamente a forma escrita como válida, mas como uma fonte equivalente de saber histórico. No mesmo patamar estão outras tipologias de fontes, como os registros imagéticos, por exemplo. Esse universo deve ser debatido com novas atribuições no que toca aos estudos históricos. O que ainda tem sido feito de forma tímida no campo é a análise de 
como essas noções racializadas informam as concepções históricas sobre o Continente africano.

Propomos aqui uma discussão sobre métodos de ensino da história da África e de seus descendentes de modo a considerar as representações construídas sobre esse espaço e sobre as pessoas vindas desse lugar. É importante destacar que não se trata de afirmar as problemáticas apontadas como uma repetição daquilo que já se sabe em relação a tais questões, mas de identificar que tais noções ainda permeiam o campo do ensino quando nos referimos à história dos povos africanos e de seus descendentes. Desse modo, este texto está localizado no debate do ensino de história desses conteúdos, em duas vias: a do ensino e a da história. A questão central é: quais possibilidades metodológicas nós temos e quais podem ser construídas para o ensino de história da África e da cultura afro-brasileira e africana?

A instituição do ensino da história africana e afro-brasileira faz repensar duas dimensões articuladoras essenciais à teoria da história: o tempo e a narrativa histórica.

Wedderburn ${ }^{10}$ aponta para a necessidade de se utilizar um tempo de longa duração e uma abordagem diacrônica no que se refere ao ensino de história da África. O autor indica que o ensino deve ser estruturado pelas relações no interior do Continente (diacronicidade intracontinental) e nas suas relações exteriores (diacronicidade extracontinental).

Ki-Zerbo e Anta Diop atuaram para legitimar uma história africana escrita e falada pelos africanos e oferecer outra leitura da história da África, uma "descolonização da história". ${ }^{11}$ Algumas leituras atribuíram a isso um caráter afrocêntrico, ${ }^{12}$ ao inferir um etnocentrismo histórico.

Gilroy sugere como perspectiva metodológica a etno-história, tendo como princípio uma relação entre as produções estéticas e culturais dos negros no espaço que ele denomina 'Atlântico Negro', resumida como uma "estrutura rizomórfica e fractal da formação transcultural e internacional” (2001, p.38). A etno-história pode ser compreendida como uma alternativa teórico-metodológica para estudar histórias de um grupo, averiguar as maneiras pelas quais surgem e emergem os discursos sobre esse grupo e suas fundamentações estéticas e filosóficas. Especificamente no que se refere à história dos africanos e de seus descendentes, sua proposta nos auxilia a compreender as maneiras pelas quais alguns grupos foram lidos e teorizados. 
Com o termo 'Atlântico Negro’ Gilroy se aproxima de uma noção de diáspora cuja ação inscreve outras possibilidades sobre as quais a história pode ser concebida ou 'imaginada' e, assim, ensinada. O autor define 'Atlântico Negro' como uma “formação política e cultural moderna” (Gilroy, 2001, p.65) e se insere na perspectiva dos estudos culturais e pós-coloniais para os quais colonialismo, racismo e modernidade são produtos de uma lógica comum de sustentação e criação conjunta. O Atlântico como metáfora de uma localização específica da produção do movimento desenvolvido de forma diaspórica. ${ }^{13}$ Nessa proposta, as roupagens culturais e políticas nas quais se constituíram a escravização e a colonização podem ser analisadas em profundidade.

Ndiaye $^{14}$ analisa a construção de uma condição negra na França e se volta para a 'invisibilidade' dos negros acordada no discurso político da República francesa, mas encontra as maneiras pelas quais sua 'visível' presença ascende historicamente na linguagem social francesa marcada pelos estereótipos em relação aos negros como grupo. $\mathrm{O}$ autor centraliza as contranarrativas dos negros na França como formas de uma construção identitária que permita que suas problemáticas sejam consideradas em suas especificidades, propondo uma história dos negros na França no modo como essa população é intrinsecamente forjada no interior da sociedade francesa.

Como desdobramento sobre a utilização de outras fontes para ensino de história da África e da cultura afro-brasileira e africana, há que se considerar, por exemplo, a noção de ressignificação que os descendentes de africanos criaram. Essa ressignificação somente foi reconhecida nas lutas contemporâneas dos africanos e seus descendentes por direitos civis equânimes e por justiça social. Nesse contexto é que a institucionalização da Lei 10.639/2003 deve ser compreendida como uma medida para uma educação das relações étnico-raciais. Tal noção pode ser articulada às noções sincréticas de crioulização e de mestiçagem nas quais se reproduz uma cultura estética diferenciada, como a música e o cinema, elementos cada vez mais focalizados nos campos dos estudos culturais que podem ser fontes interessantes para o ensino da história (Gilroy, 2001).

Para responder à questão aqui formulada acerca de uma metodologia para o ensino de história da África e da cultura afro-brasileira e africana, partimos de duas possibilidades: a categoria diáspora e a experiência dos quilombos. Em linhas gerais, este texto se preocupa com os aspectos conceituais na 
construção de uma metodologia que considere as experiências dos fenômenos que marcam as populações africanas e afrodescendentes. Busca articular essas experiências a partir da diáspora como uma categoria analítica, e dos espaços quilombolas como possibilidade de construção para o ensino desses conteúdos.

Além das questões de método indicadas até aqui, o texto está estruturado em partes interdependentes: inicialmente traça, de forma breve, a maneira pela qual os movimentos sociais negros brasileiros se apropriaram da educação, propondo mudanças na educação das relações raciais brasileiras em um processo que culminou na Lei 10.639/2003. Em seguida, desenvolve a noção de diáspora como recurso metodológico no ensino de história africana e da cultura afro-brasileira e africana. Por fim, pretende observar, recorrendo ao exemplo das comunidades quilombolas, que a educação em história e sua metodologia passam invariavelmente pelas afirmações da diversidade, pelo olhar de contextos específicos e pela clareza com que os conteúdos são inscritos e se inscrevem no cotidiano em diálogo com o passado, perpassando pelas vozes e ações de vários sujeitos.

\section{O ENSINO DE HISTÓRIA AFRICANA E AFRO-BRASILEIRA} NA EDUCAÇÃO DAS RELAÇÕES ÉTNICO-RACIAIS

O campo da educação, e em especial da história da educação, deixou ao largo as medidas normativas ${ }^{15}$ que hoje, retomadas nos estudos das relações étnico-raciais com a educação, são analisadas na pesquisa acadêmica. As ações dos movimentos sociais negros se voltaram para o incentivo à educação formal, entretanto muitos perceberam a reprodução do racismo no ensino e no seu caráter etnocêntrico, ou seja, a concepção de uma superioridade de uma cultura em relação a outras. Munidos dessa compreensão, os movimentos sociais negros passam a reivindicar junto ao Estado brasileiro o estudo da história e da cultura da África e dos afrodescendentes.

Educação e raça no Brasil foram estabelecidas em conjunto. As primeiras medidas que constituíram o sistema educacional brasileiro tinham como principal preocupação a organização da nação brasileira, e, das inúmeras medidas tomadas com esse intuito, centralizaram-se entre as décadas de 1930 e $1960^{16}$ as práticas na produção de um povo brasileiro que fosse destituído de seus caracteres étnicos, africanos e indígenas. ${ }^{17}$ As primeiras iniciativas para inser- 
ção nos currículos escolares oficiais se voltaram para o ensino da história africana e afro-brasileira, cujas ações datam das décadas de 1970 e 1980 nos denominados 'estudos africanos'. ${ }^{18}$

A Convenção Nacional do Negro pela Constituinte, de 1986, recomendou à Assembleia Constituinte de 1987: “o processo educacional respeitará todos os aspectos da cultura brasileira. É obrigatória a inclusão nos currículos escolares de I, II, e III graus do ensino da história da África e da história do Negro no Brasil". ${ }^{19}$ As legislações em nível local mostraram um processo gradativo de incorporação do ensino da temática étnico-racial como proposta de uma educação voltada para novas relações raciais.

A partir da década de 1990, as ações focaram denúncias de estereotipia em livros didáticos e de práticas preconceituosas nas escolas. Alguns municípios passaram a atender parcialmente às reivindicações legais ${ }^{20}$ dos movimentos sociais negros, os quais se organizaram e exigiram do Estado brasileiro que as ações de combate ao racismo se tornassem política de Estado. Ainda na década de 1990 a influência de organismos multilaterais e de uma concepção de educação focada na produtividade e no investimento promoveu as medidas para universalização da educação. Paulatinamente, as ações políticas dos movimentos sociais negros se reverteram em políticas educacionais para o combate ao racismo. Os Parâmetros Curriculares Nacionais (1997) corroboram a ideia de existir um currículo mínimo para o ensino básico e médio, o eixo 'Pluralidade Cultural', no qual se encaixam as questões étnico-raciais, e refletem um reconhecimento pelo Estado brasileiro da característica multicultural e racial da sociedade brasileira. No que se refere ao ensino de história, o lugar da escravização ainda era predominante nessa época, com a forte influência das leituras marxistas sobre a escravidão, por meio das quais as populações africanas e negras entraram na história a ser ensinada.

No âmbito estatal, a criação do Grupo de Trabalho Interministerial População Negra (1998), resultante da Marcha Zumbi dos Palmares Contra o Racismo pela Cidadania e a Vida (1995), se insere nas medidas de incorporação dos conteúdos relativos à história africana e afro-brasileira e nas Políticas de Ação Afirmativa. A promulgação da Lei 10.639/2003 se consolida como o resultado de uma luta histórica dos movimentos sociais negros por uma educação que contemple a diversidade e a diferença. 
O Parecer CNE/CP 003/2004 sobre as Diretrizes Curriculares Nacionais para a Educação das Relações Étnico-Raciais para o Ensino de História e Cultura Afro-Brasileira e Africana, aprovado pelo Conselho Nacional de Educação (CNE) em 2004, permitiu nortear a formulação de novas metodologias para o ensino de história, como a indicação da memória diaspórica e o estudo da história dos quilombos. A promulgação da Lei e a aprovação das Diretrizes mostram que tais medidas se voltam para a realização de uma (re)educação das relações étnico-raciais brasileiras, visto que elas operam historicamente marcadas por relações desiguais e discriminatórias.

A educação das relações étnico-raciais é uma relação de ensino e aprendizagem que perpassa as relações entre brancos e negros, sendo, por isso, plural ao considerar outras etnias e grupos de pertencimento. Destaca-se a dimensão da multiplicidade das relações étnico-raciais, a importância de posturas e identidades positivas, um pertencimento racial ressignificado. Essa concepção de educar para as relações étnico-raciais traz questionamentos e propostas de reformulação no interior das escolas e dos currículos e nas práticas de educadores.

\section{A DiÁSPORA COMO RECURSO METODOLÓGICO}

Embora surjam algumas diferenças conceituais conforme a referência teórica utilizada, a noção de diáspora acorda alguns elementos, como a noção de saída ou dispersão de um grupo para outro território. ${ }^{21}$ Uma das questões que modificam a utilização do termo é o papel da experiência da saída desses povos e a produção que constituem no lugar de chegada ou durante o trajeto de dispersão. Aqui a referência de desterritorialização, inspirada na filosofia da diferença, cunhada por Gilles Deleuze e Félix Guattari, ${ }^{22}$ articula-se de forma semelhante, já que esse sentido de movimento e mudança é central na perspectiva desses autores. Com a mesma finalidade, a noção de espaço e de suas múltiplas ocupações é fundamental. A noção de diáspora fratura o tempo e o espaço, coloca como problemática metodológica a centralidade da experiência dos povos em seus diferentes contextos, ou seja, diferentes processos diaspóricos.

As diferentes noções que a diáspora nos oferece permitem olhar de forma plural a história dos negros dispersos, reapropriada mediante inúmeros movimentos. Os movimentos pan-africanista e rastafári, por exemplo, congrega- 
ram um projeto de união identitária e de uma experiência comum das relações entre tradição e memória e uma reconstrução histórica, podendo ser articulados a outros movimentos identitários e imprimindo uma estética ao positivar os dreadlocks (cf. Cashmore, 2000).

A diáspora permite uma relação mais criativa com o tempo histórico. Já é consenso que uma historicidade baseada em trajetória linear fornece poucas possibilidades metodológicas para o ensino de história africana e de cultura afro-brasileira e africana. Quando nos voltamos para a pluralidade do universo cultural africano e de suas reminiscências na cultura brasileira, essas dimensões exigem sua revisão. Isso significa questionar a periodização do tempo na formação dos historiadores. As temporalidades da pré-história, história antiga, moderna e contemporânea partem de um tempo e um espaço a partir dos quais se define o que é antigo, moderno ou contemporâneo. Essa medição temporal é informada por uma espécie de norma e prática epistemológica que tem como centralidade o espaço e o tempo ocidentais, mais especificamente europeus.

Ainda como recurso temporal, a diáspora distorce as temáticas de origem e volta, relacionando-as a uma concepção de espaço como dispersão e pertencimento a uma comunidade configurada fora das noções arraigadas de um Estado-nação, forjando termos como 'africanos da diáspora'. O pensamento judaico no qual a ideia de diáspora se desenvolveu articulou essas noções de pertencimento, permitindo uma identificação judaica dispersa, unida por pressupostos religiosos e culturais.

A diáspora permite um conjunto ampliado de sentidos cujo alargamento pode ser visualizado no modo como a história desses povos tem sido considerada de forma interna aos seus processos de dispersão. Isso pode ser visto nas maneiras pelas quais as experiências de colonização têm articulado colonizados e colonizadores de forma diferenciada e interna à estrutura colonial e pós-colonial (Hall, 2009).

Ao colocarmos analiticamente a diáspora na construção metodológica inventamos uma cisão na relação espaço/tempo. Diante de tais caminhos a diáspora se constitui como uma alternativa com a qual é possível ensinar a história dos africanos e de seus descendentes. Na história da África, o Continente não aparece como um lugar predefinido, mas como um constructo plural, e, para que seu ensino compreenda essa pluralidade dinâmica, requer-se o uso de alternativas e ferramentas metodológicas. 
Para responder a essa outra relação com o tempo e o espaço é necessário construir outra metodologia histórica, e a diáspora nos possibilita essa nova construção, na medida em que ela rompe com um tempo histórico teleológico, linear, e nos permite analisar fenômenos como a colonização pela resistência dos povos colonizados e pela relação estabelecida entre eles nos espaços colonizados. Como afirma Gilroy (2001), a diáspora ativa noções de temporalidade e memória desde a perspectiva dos subordinados. É possível articular a ladainha dos escravizados durante o trabalho, as músicas de resistência das descolonizações africanas cantadas por Bob Marley e as letras de rap contemporâneas para compreender como os africanos e seus descendentes têm utilizado culturalmente a música como produção e resistência às suas condições. É possível construir aulas que utilizem as poesias da négritude produzidas na França, os movimentos de libertação colonial dos países africanos e as produções cinematográficas sobre as lutas pós-coloniais.

A história africana pode ser ensinada desde a noção de oralidade dos Griôs até a produção literária africana contemporânea, das lutas de mulheres e homens pela liberdade até a resistência pela escolha do suicídio à escravidão (Gilroy, 2001). É, portanto, necessária outra temporalidade para o ensino desses conteúdos, e a noção de diáspora é particularmente rica, pois ela rompe com a periodicidade comum ao campo historiográfico do qual a maioria dos cursos de formação de historiadores no Brasil é adepto.

Os estudos pós-coloniais têm buscado problematizar os cânones históricos e rever a história desses povos. A colonização, por exemplo, desponta da escravização em uma relação hierárquica e coloca em cena a resistência, a negociação e a subversão como elementos centrais das relações na colonização. Um fator essencial nesse processo é a identificação dos trabalhos que construíram suas análises nessa dimensão e pouco avançaram em uma mudança na concepção dessa temática.

O termo "pós" opera uma quebra no tempo, visto que o termo pós-colonial como teoria se alia aos outros "pós" feminismo, colonialismo, modernismo -, mas não do ponto de vista de uma produção teórica diferenciada, 'após' (no sentido de continuidade) tais períodos, e sim como um novo olhar sobre a maneira pela qual conceitos e noções são construídos. O 'pós' reúne espaços distintos e reorganiza suas temporalidades, rompe com categorizações binárias e nos obriga a considerar os conceitos em suas relações contingentes, relacio- 
nais e históricas. Permite compreender de que maneira discursos racializados são contados, narrados de forma repetida, cotidianamente, ${ }^{23}$ formando tropos estereotipados com os quais se criam as ideias que temos sobre os africanos e os afrodescendentes.

A diáspora nos auxilia também a operar o caráter contingente da história, possibilitando uma historicidade aos eventos - estudar e compreender como eles se tornam históricos e qual lugar ocupam na história. Para o ensino de história que pode utilizar a dimensão diaspórica como recurso sugere-se a apresentação dos eventos históricos de forma não linear, articulando temáticas que comumente aparecem separadas nos cursos de história e em boa parte dos materiais didáticos disponíveis. Aqui entra o quilombo.

\section{O ESPAÇO DAS COMUNIDADES QUILOMBOLAS}

Para aludir às comunidades quilombolas, marcaremos, em princípio, o lugar onde as consideramos para este texto. Pensamos o quilombo de forma diaspórica. Consideramos a historiografia que busca compreender o movimento das comunidades quilombolas voltando-se para o seu surgimento e para as relações que elas estabeleceram com outros grupos. No entanto, colocamos o quilombo diasporicamente ao lado desse campo consolidado da pesquisa sobre quilombos. Pensá-lo de forma diaspórica centraliza o espaço e seu movimento.

Entre as principais referências históricas e sociológicas das comunidades quilombolas está a visão de que elas atuaram por um lado como uma insurreição ao escravismo e, por outro, como uma experiência de sociedades marcadas por elementos pluriculturais. ${ }^{24}$ Em alguns momentos elas se opuseram ao governamento estabelecido no Brasil, mantendo-se de forma constante na história brasileira (Moura, 1988). Isso exige retomarmos o fato de que os quilombolas, majoritariamente africanos e descendentes, ressignificaram seu papel como comunidades resistentes ao escravismo brasileiro, o que não impediu a presença no interior do espaço quilombola de pessoas como desertores e perseguidos. ${ }^{25} \mathrm{Ou}$ ainda, "índios, perseguidos, mulatos, curibocas, pessoas perseguidas pela polícia, bandoleiros, devedores do fisco, fugitivos do serviço militar, mulheres sem profissão, brancos e prostitutas" (Munanga, 2004, p.34), cujos registros de participação em muitas comunidades quilombolas apontam formas de socialibilidade entre esses grupos que escapavam à hierarquia social 
da época. Munanga destaca que "imitando o modelo africano, eles transformaram esses territórios em espécie de campos de iniciação à resistência, campos esses abertos a todos os oprimidos da sociedade ... prefigurando um modelo de democracia plurirracial" (2004, p.63) ou pluricultural.

Há inúmeros processos históricos de ressemantização para designar as experiências de resistência à opressão dos negros no Brasil e em outros países. Entre eles há pluralidade de termos: quilombos, quilombolas, mocambos e comunidades remanescentes de quilombo são exemplos desse processo. A palavra, de acordo com o contexto histórico, tem apresentado significados diferentes, apontando transformações de ordem semântica e prática em sua utilização. Assim, estudar quilombos no século XVII remete a características diferentes do que encontraremos nos séculos XVIII e XIX. Distancia-se de nós a denominação atribuída aos quilombos como "refúgios de escravos fugidos", ${ }^{26}$ mas, ao serem ressignificados, despontam noções sobre as formas de lutas contra as investidas de destruição dos quilombos e resistências solidárias. ${ }^{27} \mathrm{~A}$ prática da quilombagem à época era também marcada pelo assalto, pelo sequestro de outros escravizados, pela formação de famílias e pela recriação de aspectos culturais africanos (Reis, 1996).

O histórico da existência de quilombos não se restringe ao Brasil. Grupos de diferentes denominações (palanques na Colômbia, México, Equador e Cuba; cumbes na Venezuela; marrons no Haiti, nas ilhas do Caribe Francês, Suriname, Estados Unidos, Guiana e Jamaica; cimarrons na América Espanhola, marrons e bush negroes na Guiana Francesa) ${ }^{28}$ expressaram e expressam em diferentes localizações a inconformidade com um sistema de exclusão social e opressão, principalmente aos negros e seus descendentes, mas que também se estende aos camponeses, pobres e marginalizados. Firmaram-se como espaço político e social de domínio dos excluídos, espaços de resistência.

Atualmente, uma característica comum às comunidades quilombolas dos séculos XX e XXI é o traço da luta, prioritariamente luta pela terra. Tal ação vem sendo acompanhada por vários setores da sociedade organizados em grupos de reivindicação social, com destaque para os movimentos sociais negros. No âmbito legislativo, a mais significativa conquista é voltada ao conteúdo do Art. ${ }^{\circ} 68$ das Disposições Transitórias da Constituição Brasileira de 1988, que prevê: 
$\$ 68^{\circ}$ Aos remanescentes das Comunidades de Quilombos que estejam ocupando suas terras é reconhecida a propriedade definitiva, devendo o Estado emitir-lhes os respectivos títulos. ${ }^{29}$

Além do direito à permanência na terra, o processo de reconhecimento assegura a posse da terra a esses grupos, coletivizando-a, obedecendo a princípios que propõem "utilização do solo e recursos naturais em geral, de forma ecologicamente equilibrada, por interesse histórico, cultural, científico, público, econômico e por justiça social". ${ }^{30}$

Segundo Clóvis Moura o quilombo foi uma forma de resistência ao escravismo, representativa na medida em que conheceu registros durante todo o período escravista e mantém uma noção de 'recriação' aos modos de vida de alguns reinos africanos, como especialmente em Palmares. ${ }^{31} \mathrm{O}$ enfoque de Moura é importante, pois constrói a análise por meio da ação do escravizado, fornecendo uma análise da unicidade atribuída ao escravizado negro - sua passividade. O autor se junta a outros, como Décio Freitas, que empreenderam uma crítica historiográfica e sociológica ao estudo das revoltas escravas e da noção de democracia racial presente à época de suas publicações. Contemporaneamente, sua característica de resistência persiste para ser preservada como um espaço do campo, ${ }^{32}$ sendo denominados como 'comunidades remanescentes de quilombo'.

Com base nessa proposição, comunidades de todo o Brasil vêm buscando o reconhecimento como quilombolas. Com ressalvas ao termo 'remanescentes', alvo de discussões e embates, cabe ao grupo considerar-se 'quilombola' e se autodefinir como tal, traçando seu percurso histórico, cultural e étnico. De acordo com a legislação, ${ }^{33}$ ser remanescente de quilombo está diretamente associado ao uso que se faz das 'terras de preto' e ao processo histórico-cultural que alicerça o grupo. Como várias comunidades ainda se encontram em processo de reconhecimento, salientamos que o que se observa - além do reconhecimento ou titulação de cunho legal - é o interior desses espaços, denominando-os indistintamente como comunidades quilombolas, e seus habitantes, como quilombolas. Embora conscientes de seu processo dinâmico de formação e das várias interferências culturais a que estão atreladas, dedicamos maior atenção à relação que essas comunidades constroem com uma ancestralidade africana, sua cultura, história e diálogo com o presente. Como pro- 
dução de resistência, a ação dos quilombos passa a ser denominada de quilombagem, articulando-se com a ação dos movimentos sociais negros contemporâneos, o que permite ao historiador em sala de aula construir analogias entre as formas de resistência atuais.

\section{EDUCAÇÃO QUILOMBOLA}

Na consideração das diretrizes que propõem o ensino de história da África e cultura africana e afro-brasileira algumas possibilidades são abertas. A primeira retoma a linguagem, ao observarmos que os livros, artigos e materiais didáticos que fazem referência ao quilombo trazem em sua maioria uma imagem de Zumbi ou uma imagem de um espaço quilombola do período colonial, produzindo uma determinada linguagem que é retomada quando se atêm a esse tema. É possível recriar uma revisão do 'quilombo histórico', trazendo para nosso cotidiano as comunidades quilombolas hoje, observando sua produção histórica, cultural e modo de viver e fazer educação. Pode-se atentar a essa construção com aulas a respeito da constituição dos quilombos, sua atual luta pela terra e os diversos conflitos agrários presentes na sociedade brasileira.

Em ambas as possibilidades, podemos tratá-las diasporicamente, repensando uma estrutura metodológica do ensino de história, o que pode ir além das estratégias convencionais de leitura e compreensão de textos didáticos. Tal ideia segue o princípio de que é necessário considerar o próprio dado constitutivo do ensino de história e da própria história, ou seja, reconhecer que a história como disciplina científica ou forma de pensamento infere o "olhar retrospectivo sobre os objetos, a certeza de que cada uma das realidades que observamos no presente pode e deve ser mais bem compreendida através do conhecimento de sua inserção no tempo". ${ }^{34}$

A título de exemplo, podemos considerar as práticas desenvolvidas no âmbito de pesquisa etnográfica junto à Comunidade Remanescente de Quilombo de Bombas, no interior do estado de São Paulo. ${ }^{35} \mathrm{O}$ trabalho teve enfoque na experiência da ludicidade infantil e nos saberes produzidos com e entre as crianças na comunidade, observando também a relação entre o lúdico e a construção de conhecimentos genuínos da comunidade entre os demais habitantes. Há uma dimensão pedagógica inserida na comunidade, que figura no lugar do que se denomina educação não formal. A ideia é que se pode aprender 
história além do que está no livro didático ou apostila, mas que é possível compreendê-la, ensiná-la e aprendê-la na dinâmica em que estamos inseridos, transformando a lógica do "currículo uniforme", ${ }^{36}$ pois o considerado "não saber' também é conhecimento.

Em linhas gerais, a comunidade apresenta aspectos peculiares quanto à sua formação e organização. Localizada no centro da floresta, prescinde de saneamento básico, energia elétrica ou estrada, tendo seus moradores de se deslocar por trilhas. A organização social é marcada por papéis definidos, fortemente marcados pelo gênero, prefigurando uma dimensão 'invisível' ${ }^{37}$ das normas sociais válidas no interior da comunidade.

O plural se apresenta como uma diversidade de jogos, brincadeiras e situações lúdicas. Dentre os mais conhecidos estão a mancala e pernas de pau, que permitem ver como as crianças em diversos espaços inspiram suas brincadeiras a partir de referências culturais - no caso citado, matrizes africanas -, embora elas também estejam conectadas com a sua contemporaneidade, como nos momentos em que brincam com o celular. Hoje, o lúdico assume forma variada, transitando entre o saber local e os saberes advindos do convívio com outros espaços e pessoas. Por exemplo, os mais jovens ouvem músicas como o rap, como os jovens que vivem nas cidades, mas não deixam de ouvir canções sertanejas e conhecem danças tradicionais como o fandango.

$\mathrm{Na}$ comunidade existem escolas iniciadas com as pessoas do local: os que mais sabiam ensinavam aos outros, até o reconhecimento pelo poder público municipal. Quando essas iniciativas foram reconhecidas como escolas públicas, os professores que passaram a atuar deixaram de ser necessariamente do entorno e trouxeram outras referências, normalmente de experiência urbana. Os materiais didáticos utilizados partem de outra realidade e pouco ressoam no fazer cotidiano dos habitantes de Bombas. Uma vez que essas escolas fazem parte da rede municipal, os materiais didáticos, sobretudo apostilas indicadas pela Secretaria de Educação, uniformizam o conhecimento, sem atentar para a diversidade do conhecimento ou para as especificidades do contexto. Deslocam, quando não renegam, os saberes produzidos pela comunidade.

Tornando mais claro: as narrativas do grupo recuperam tradições que dialogam com o passado e o presente, com a história, trazendo elementos (categorias do saber histórico) como trabalho, terra, tempo, espaço, ocupação territorial, exploração capital, classe social, divisão de trabalho, gênero, rela- 
ções raciais, cultura e sociedade. Exemplo: um dos moradores mais antigos conta que seu pai nunca teve documento, e que ele, o filho, no dia em que o pai faleceu, tirou "os dois documentos: o de nascimento e o de morte".

Com base nesse relato, e em vários outros, é possível a um professor de história do ensino fundamental e mesmo do ensino médio abordar algumas questões históricas. Brincadeiras como o canjém, um tipo de balanço, e tilimbuque, espécie de gangorra, apontam para saberes em que a notoriedade centra-se no corpo, como espaço de experimentação, e na linguagem, que revela o processo de significação próprio da comunidade, pois essas brincadeiras, da maneira como acontecem, só podem ocorrer na floresta: para se balançar no canjém é preciso um cipó forte para cruzar determinado espaço, de um ponto a outro; quanto ao tilimbuque, construção com restos de toras de madeira, carece do conhecimento dos mais velhos tanto para fazer a armação desse tipo de gangorra, quanto para a escolha das madeiras resistentes o suficiente para servirem de base.

O diálogo com sujeitos até então silenciados, ou classificados na categoria coadjuvante ou figurativa, inverte a proposição do ensino denominado tradicional em história. A oralidade, muito presente em histórias, causos, lendas e cantos, traça a identidade dos habitantes em meio à diversidade e marca outra relação com o conhecimento, levando em consideração aquilo que ainda não foi padronizado ou estereotipado nos livros didáticos.

\section{CONSIDERAÇÕES FINAIS}

Autores do campo de ensino de história ${ }^{38}$ têm demonstrado que a área não pode se constituir por meio de uma história única, seja ela calcada nos livros didáticos, manuais de ensino ou apostilas, seja em uma única referência - a eurocêntrica, por exemplo -, consolidando um ensino "com pouca crítica e pouca criatividade" (Fonseca, 2010). Apontam também lacunas no processo de formação do professor de História, principalmente o desgaste do campo com a proposição, na década de 1970, da formação em curso único para História e Geografia, na extinta grade dos Estudos Sociais. A perda da especificidade e da reflexão em torno do ensinar e aprender história ainda é observada em instituições escolares onde primam o livro, o resumo e o questionário como tripé do ensino. Porém, o licenciado em história não é o único a trabalhar 
com seu ensino: nos primeiros anos de escolarização os pedagogos são responsáveis por articular o campo, e nem sempre a formação desses profissionais atenta para as demandas do ensino de história, fato que pode gerar equívocos e consequências nos anos posteriores. É nesse cenário que se insere o desafio de ensinar e aprender história no século XXI.

No decorrer do debate proposto neste texto foram trabalhadas algumas questões epistemológicas e metodológicas sobre o ensino de história e cultura afro-brasileira e africana. A questão do método é um dos pontos chaves na perspectiva do ensino, especialmente no que toca ao ensino de história. Destaca-se assim a categoria diáspora e a dimensão dos quilombos como alternativas metodológicas criativas para ensinar a história das populações africanas e de seus descendentes.

Tais noções rompem com os elos nodais na construção do conhecimento histórico. Rompimento, aqui, não significa uma ruptura vazia na qual a proposta seria trocar uma perspectiva pela outra, romantizando a história e seu ensino, mas potencializar diversas formas de construir metodologias conforme o conteúdo a ser ofertado. Implica considerar as especificidades locais e regionais de escolas, perfis de estudantes e professores, o que permite ampliar as formas de ensinar história. Em relação ao estudo de história da África e cultura afro-brasileira e africana as características específicas sobre o lugar dessas temáticas no ensino da história é fundamental. Aqui consideramos que o ensino desses conteúdos específicos deve ser construído de forma orgânica na preparação da didática dos conteúdos.

Os cursos de formação de profissionais da educação sobre a temática da educação das relações étnico-raciais apontam que esses profissionais mantêm uma ideia estereotipada sobre o Continente africano e sobre as pessoas que habitam esse espaço. Muitos tiveram pouca ou nenhuma incursão nesses conteúdos, durante sua trajetória escolar. Com os historiadores em formação isso se repete, sendo flagrantes nas salas de aulas as opiniões ainda enviesadas sobre os africanos e seus descendentes. A publicação em português da Coleção História Geral da África, ${ }^{39}$ sob indicação da Unesco, vem agir no sentido de disponibilizar um material denso sobre a história do Continente africano. A descrição dos capítulos por historiadores dedicados ao tema da história africana revela postura que aponta para uma construção histórica sobre os africanos e suas produções culturais, de forma a considerar suas especificidades, e permi- 
te aos profissionais do ensino de história buscar fontes diversas como mapas, relatos e imagens para compor uma didática para o ensino da história africana e de seus descendentes.

O grande desafio para estudantes e professores está na busca de tais fontes e documentos. Deve-se considerar que uma das possibilidades de 'releitura' concentra-se nas próprias fontes oriundas da história considerada tradicional. O trabalho com todo tipo de iconografia, ${ }^{40}$ mitos, ${ }^{41}$ diários de viagem, ${ }^{42}$ contos tradicionais, provérbios, ${ }^{43}$ filmografia ${ }^{44}$ e literatura ${ }^{45}$ pode ser ressignificado a partir da apresentação e discussão do conceito de quilombo para além do 'refúgio de escravos fugidos', aproximando os alunos de outra referência para os quilombolas. Tais possibilidades podem auxiliar o professor a trazer as experiências dos estudantes para a sala de aula. Embora esse discurso tenha se tornado lugar-comum na educação, só é possível pensar uma inter-relação com a dimensão quilombola ouvindo de fato o que essas pessoas têm a dizer sobre si mesmas e suas histórias, observando e registrando seu cotidiano e fazeres. É preciso considerar as experiências desses espaços e o que podem nos ensinar sobre formas de sociabilidade, saberes tradicionais e relações intergeracionais, entre outras experiências.

Contemporaneamente o fenômeno do racismo e a percepção das diferenças são condicionados a uma confluência de elementos, língua, nacionalidade e religião. Operam em uma processualidade que configura nossa apreensão das diferenças, e esse movimento é instável e contingente. Todo esse universo abrange características específicas no ensino de história da África e das culturas de seus povos e descendentes.

Esses conteúdos nos colocam também o desafio de repensar a função do ensino de história e a importância de seu estudo. Não se pode ensinar sobre a história dos povos africanos e o movimento da diáspora negra sem compreender as experiências diaspóricas vividas por esses grupos. Não se pode também ignorar a estrutura e a funcionalidade do racismo brasileiro e sua perpetuação mesmo no ambiente escolar. Tal postura exige que tenhamos uma compreensão da presença das várias faces em que o fenômeno do racismo se perpetua, e nesse sentido o ensino de história e da cultura dos africanos e de seus descendentes nos oferece um caminho para uma história plural. 


\section{NOTAS}

${ }^{1}$ CASTRO, Amélia D. O ensino: objeto da didática. In: CARVALHO, Anna Maria P. de. Ensinar a ensinar: didática para a escola fundamental e média. São Paulo: Cengage Learning, 2001. p.13-29.

${ }^{2}$ ANDERSON, Benedict. Comunidades imaginadas: reflexões sobre a origem e a difusão do nacionalismo. Trad. Denise Bottman. São Paulo: Companhia das Letras, 2008. p.330.

${ }^{3}$ Não esqueçamos o contexto e o impacto da análise de Hegel sobre a ausência da história dos povos negros africanos à época, "A África não é uma parte histórica do mundo" (HEGEL, G. W. F. Filosofia da História. Brasília: Ed. UnB, 1995, apud OLIVA, Anderson Ribeiro. A história da África nos bancos escolares: representações e imprecisões na literatura didática. Est. Afro-Asiáticos, v.25, n.3 p.421-461, 2003; p.438) e o fato de que textos como esses continuam ainda hoje a ser lidos nos cursos de formação de historiadores.

${ }^{4}$ FANON, F. Pele negra, máscaras brancas. Trad. Renato da Silveira. Salvador: Ed. UFBA, 2008.

${ }^{5}$ GILROY, Paul. O Atlântico Negro: modernidade e dupla consciência. Rio de Janeiro: Ed. 34, 2001. p.432; MIGNOLO, W. D. La idea de América Latina: la herida colonial y la opción descolonial. Barcelona: Gedisa Ed., 2007. p.240.

${ }^{6}$ BHABHA, Homi K. O local da cultura. Trad. Myriam Avila, Eliana Lourenço L. Reis, Glaucia R. Gonçalves. Belo Horizonte: Ed. UFMG, 1998. p.238.

${ }^{7}$ HALL, Stuart. Da diáspora: identidades e mediações culturais. Org. Liv Sovik. Belo Horizonte: UFMG, 2009. p.410.

${ }^{8}$ Movimento artístico e político criado por intelectuais negros de maioria da língua francesa, na década de 1930, que produziu uma crítica literária ao colonialismo e ao racismo.

${ }^{9}$ MUNANGA, Kabengele. Rediscutindo a mestiçagem no Brasil: identidade nacional versus identidade negra. Belo Horizonte: Autêntica, 2004. p.150. (Col. Cultura e Identidade Brasileira).

${ }^{10}$ WEDDERBURN, Carlos Moore. Novas bases para o Ensino da História da África no Brasil. In: Educação Anti-racista: caminhos abertos pela Lei Federal 10.639/2003. Brasília: Secad/MEC, 2005. p.134-142.

${ }^{11}$ CURTIN, P. D. Tendências recentes das pesquisas históricas africanas e contribuição a história em geral. In: KI-ZERBO, Joseph (Org.) História Geral da África. 2.ed. rev. Brasília: Unesco, 2010. p.44.

${ }^{12} \mathrm{O}$ termo afrocêntrico se refere a uma perspectiva aplicada ao modo de estudar as temáticas relativas ao continente africano por uma perspectiva orgânica, pensada desde o início a partir de uma forma específica de operar o tempo e a narrativa acerca das experiências africanas (ASANTI, in: CASHMORE, Ellis. Dicionário de relações étnicas e raciais. Trad. Dinah Kleve. São Paulo: Selo Negro, 2000. 598p. p.62-64). 
${ }^{13}$ Cf. THORTON, J. A África e os africanos na formação do mundo atlântico 1400-1800. Rio de Janeiro: Elsevier; Campus, 2004.

${ }^{14}$ NDIAYE, Pap. La condition noire: essai sur une minorité française. Paris: Gallimard, 2008. p.501.

${ }^{15}$ Referimo-nos ao decreto imperial de 1870, que impedia o acesso de negros escravizados às escolas, entre outras leis que impediam o acesso a africanos livres ou libertos.

${ }^{16}$ Estamos nos referindo às medidas legislativas de caráter estatal, no entanto não desconsideramos as propostas pedagógicas das associações negras como, por exemplo, o Teatro Experimental do Negro (TEN) e da Frente Negra Brasileira.

${ }^{17}$ DAVILA, Jerry. Diploma de brancura. Política social e racial no Brasil - 1917-1945. São Paulo: Ed. Unesp, 2006. p.399.

${ }^{18}$ PINTO, R. P. Movimento negro e a educação do negro: a ênfase na identidade. Cadernos de pesquisa, São Paulo, n.86, p.25-38, 1993.

${ }^{19}$ SANTOS, S. A. A lei 10.639/03 como fruto da luta anti-racista do Movimento Negro. SECAD. Educação anti-racista: caminhos abertos pela Lei Federal nº 10.639/03. Brasília, 2005. p.21-38.

${ }^{20}$ Nas leis de Porto Alegre em 1991, de Belém em 1994, na disciplina de História. Para a efetivação dos conteúdos na disciplina, as leis propõem, de maneira geral, levantamento de bibliografia específica, reuniões e organização de seminários. Em 1994, o município de Aracaju institui curso preparatório para a inclusão de conteúdos relativos à História e Cultura do negro e do índio na rede de ensino. Em 1994 o município institui o ensino da 'Raça Negra'. Em São Paulo, no ano de 1996, o município institui os 'estudos contra a discriminação racial'; em Brasília, também em 1996, os conteúdos relativos à 'Raça Negra' são incluídos no sistema de ensino do Distrito Federal.

${ }^{21}$ WIEVIORKA, M. O racismo: uma introdução. Trad. Fany Kon. 1.ed. São Paulo: Perspectiva, 2007. p.164.

22 DELEUZE, G.; GUATTARI, F. Mil platôs: capitalismo e esquizofrenia. v.5. Trad. Peter Pál Pelbart e Janice Caiafa. São Paulo: Ed. 34, 1997. p.235.

${ }^{23}$ Valentin Mudimbe chama de discours subreptices um determinado modo pelo qual os discursos são construídos e repetidos. Ver em NDIAYE, 2008.

${ }^{24}$ Cf. em Quilombismo (2.ed. Brasília: Fundação Cultural Palmares; OR Ed., 2002) a análise de Abdias do Nascimento da proposta de 'Estado quilombista'.

${ }^{25}$ REIS, João J. Quilombos e revoltas no Brasil. O povo negro no Brasil. Revista da USP, São Paulo, v.28, p.14-39, 1996. p.16.

${ }^{26}$ No século XVI, o Conselho Ultramarino denominava quilombo como "toda habitação de negros fugidos que passem de cinco, em parte despovoada, ainda que não tenham ranchos levantados nem se achem pilões neles" (MOURA apud MUNANGA; GOMES, 2006, p.70). Já no século XIX, a lei Provincial 157 (9 ago. 1848, Rio Grande do Sul) define: "por 
quilombo entende-se a reunião no mato ou em lugar oculto de mais de três escravos" ou "habitação clandestina nas matas e desertos que serviam de refúgio a escravos fugidos". PINHO, José Ricardo Moreno. Escravos, quilombolas ou meeiros: escravidão e cultura política no meio São Francisco (1830-1888). Dissertação (Mestrado) - UFBA. Salvador, 2001. p.84.

${ }^{27}$ MUNANGA, Kabengele; GOMES, Nilma Lino. O negro no Brasil de hoje. São Paulo: Global, 2006. p.9-140.

${ }^{28}$ Cf. ANJOS, Rafael; CIPRYANO, André. Quilombolas: tradições e cultura da resistência. São Paulo: Aori Comunicação, 2006.

${ }^{29}$ ITESP. Negros do Ribeira: reconhecimento étnico e conquista de território. São Paulo, 2000 (Cadernos ITESP, 3). p.3.

${ }^{30}$ ITESP, 2000, v.3, p.8. A questão da ressemantização do termo 'quilombo', passando por quilombolas e comunidades remanescentes de quilombos, tem sido pauta de vários estudos, dentre os quais se destaca ARRUTI, José Maurício. Mocambo: antropologia e história do processo de formação quilombola (Bauru: Edusc, 2006), que traça não apenas o histórico desse processo como também as relações implicadas no âmbito das políticas públicas.

${ }^{31}$ MOURA, Clóvis. Rebeliões da senzala. 4.ed. Porto Alegre: Mercado Aberto, 1988. p.2425.

${ }^{32}$ Todavia, é importante destacar que entre os quilombos contemporâneos, comunidades urbanas também têm direito à nomeação e titulação como quilombolas, como é o caso da Comunidade de Brotas, em São Paulo.

${ }^{33}$ Decreto 4.888 de 10 nov. 2003: "a caracterização dos remanescentes das comunidades dos quilombos será atestada mediante autodefinição da própria comunidade ... com presunção de ancestralidade negra relacionada com a opressão historicamente sofrida" (cf. MATTOS, H. Remanescentes das comunidades dos quilombos: memória do cativeiro e políticas de reparação no Brasil. Revista USP, São Paulo, n.68, p.104-111, 2005-2006).

${ }^{34}$ CERRI, L. F. Uma proposta de mapa do tempo para artesãos de mapas do tempo: história do ensino de História e didática da História. In: MONTEIRO, A. M.; GASPARELLO, A. M.; MAGALHÃES, M. S. (Org.) Ensino de História: sujeitos, saberes e práticas. 1.ed. Rio de Janeiro: Mauad X; Faperj, 2007. v.1, p.59-72. p.60.

${ }^{35}$ SANTOS, Maria Walburga dos. Saberes da Terra: o lúdico em Bombas, uma comunidade quilombola (estudo de caso etnográfico). Tese (Doutorado em Educação) - Faculdade de Educação, USP. São Paulo, 2010.

${ }^{36}$ FORMOSINHO, João. O currículo uniforme, pronto a vestir, de tamanho único. Mangualde (Portugal): Ed. Pedago, 2007.

${ }^{37}$ Cf. MOURA, G. o aprendizado nas comunidades quilombolas: o currículo invisível. In: BRAGA, Maria Lúcia de S.; SOUZA, Edileuza P. de; MAGALHÃES PINTO, Ana Flávia (Org.) Dimensões da inclusão no Ensino Médio. Brasília: MEC; BID; Unesco, 2006. p.259- 
270. Disponível em: unesdoc.unesco.org/images/0014/001463/146328por.pdf; Acesso em: 21 abr. 2012.

${ }^{38}$ CIAMPI, Helenice. A História pensada e ensinada: da geração das certezas à geração das incertezas. São Paulo: Educ; Fapesp, 2000; BITTENCOURT, Circe Maria Fernandes. Ensino de História: fundamentos e métodos. São Paulo: Cortez, 2009; FONSECA, Selva Guimarães. Caminhos da História ensinada. Campinas (SP): Papirus, 2010.

${ }^{39}$ A coleção composta por oito volumes foi publicada em 1981, em inglês, e em 2010 foi publicada em português por uma parceria entre a Unesco, o Ministério da Educação e a Universidade Federal de São Carlos. Disponível em: www.unesco.org/new/pt/brasilia/ about-this-office/single-view/news/general_history_of_africa_collection_in_portuguese-1/; Acesso em: 21 abr. 2012.

${ }^{40}$ As 'pranchas' tradicionais de Debret, por exemplo, para serem problematizadas e discutidas à luz dos conceitos de diáspora e quilombos.

${ }^{41}$ Observar os trabalhos de Roger Bastide e Reginaldo Prandi.

${ }^{42}$ Trabalhos de Vanhargen, orientando leituras e promovendo reflexões. Cf. LAPA, José R. A. História e Historiografia do Brasil pós 64. São Paulo: Paz e Terra, 1985.

${ }^{43}$ Obras de Luís da Câmara Cascudo, no caso de contos tradicionais, folclóricos e provérbios.

${ }^{44}$ Além de filmes do circuito comercial, observar a produção de documentários como Quilombos da Bahia (dir. Antônio Olavo. Salvador: Portfolium, 2005).

${ }^{45}$ Cf. AMÂNCIO, I. M. C.; GOMES, N. L.; JORGE, M. L. S. Literaturas africanas e afro-brasileira na prática pedagógica. Belo Horizonte: Autêntica, 2008. p.168.

Artigo recebido em 10 de janeiro de 2012. Aprovado em 23 de abril de 2012. 